\title{
Purification, crystallization and preliminary diffraction studies of AcrB, an inner-membrane multi-drug efflux protein
}

\section{Klaas M. Pos ${ }^{\mathrm{a} *}$ and Kay Diederichs $^{\mathbf{b}}$}

anstitut für Mikrobiologie, D-Biol, ETH Zürich Schmelzbergstrasse 7, CH-8092 Zürich, Switzerland, and ${ }^{\mathbf{b}}$ Fachbereich Biologie, Universität Konstanz, M656, D-78457 Konstanz, Germany

Correspondence e-mail: pos@micro.biol.ethz.ch
Resistance of pathogens to antibiotics is often dependent on multidrug export proteins that reside in the inner membrane of bacteria. This work describes the expression, purification, crystallization and preliminary crystallographic analysis of AcrB of Escherichia coli. Together with AcrA and TolC, AcrB forms a proton motive force dependent efflux pump of the resistance-nodulation-cell division (RND) transporter superfamily and is responsible for resistance towards many common antibiotics such as ciprofloxacin and novobiocin. AcrB crystallizes in space group R32, with unit-cell parameters $a=b=143, c=513 \AA$; the crystals diffract to $3.0 \AA$ resolution.
Received 15 May 2002

Accepted 5 August 2002

\section{Introduction}

Multi-drug resistance of common pathogens is one of the most serious health threats in the modern industrial world (Felmingham \& Washington, 1999). Resistance is often associated with the overproduction of innermembrane proteins that are capable of extruding antibiotics and in many cases also detergents, dyes and organic solvents. Multiple antibiotic resistant Escherichia coli strains have been shown to overproduce two proteins, AcrA and AcrB (Okusu et al., 1996). These proteins are encoded by the acr $A$ and $a c r B$ genes, which form an operon and are under the control of the regulator protein AcrR. AcrB belongs to the RND (resistance-nodulationcell division) transporter superfamily (Tseng et al., 1999) and, together with AcrA and the outer-membrane component TolC, transports drugs directly into the medium, bypassing the periplasmic space and outer membrane (Fralick, 1996; Tseng et al., 1999; Zgurskaya \& Nikaido, 2000a,b; Koronakis et al., 2000; Nikaido \& Zgurskaya, 2001).

The AcrAB-TolC complex is a major contributor to resistance in $E$. coli to drugs and antibiotics such as ciprofloxacin, novobiocin, erythromycin, tetracycline, chloramphenicol and cloxallin (Okusu et al., 1996; Zgurskaya \& Nikaido, 2000a; Koronakis et al., 2000; Nikaido \& Zgurskaya, 2001).

Both AcrA and AcrB have been purified and successfully reconstituted into liposomes (Zgurskaya \& Nikaido, 1999). It has been shown that the inner-membrane protein AcrB is a proton motive force dependent efflux protein $\left(\mathrm{H}^{+}\right.$/antibiotic and $\mathrm{H}^{+}$/bile salt antiporter) and that AcrA is involved in the connection between AcrB and TolC, thus spanning the periplasmic space (Zgurskaya \&
Nikaido, 2000b). The efflux of the toxic compounds across two membranes in Gramnegative bacteria results, in combination with the low permeability of the outer membrane, in a synergistically increased resistance towards the drug.

Recently, structural data on AcrA have been published at a resolution of $20 \AA$ (Avila-Sakar et al., 2001). We describe here the successful crystallization and preliminary X-ray diffraction studies of the inner-membrane protein AcrB.

\section{Material and methods}

\subsection{Protein expression and purification}

For routine work with recombinant DNA, established protocols were used (Sambrook et al., 1989). For the construction of the $\mathrm{AcrB}_{\mathrm{His}}$ expression plasmid, the $a c r B$ gene was amplified from chromosomal $E$. coli DNA using the oligonucleotides acrBfor (5'-GGATCCCATATGCCTAATTTCTTTATCGATC-3') and acrBrev (5'-AAGCTTCTCGAGATGATGATCGACAGTATGGCTG-3'). In acrBfor, the ATG start codon of $a c r B$ is part of an $N d e$ I restriction site, which is preceded by a $B a m \mathrm{HI}$ restriction site (six additional nucleotides) to increase restriction efficiency. In acrBrev, an XhoI restriction site has been introduced after the last codon encoding an amino acid.

The PCR mixture contained $500 \mathrm{ng}$ genomic E. coli DNA, $0.4 \mu M$ of each primer, $0.2 \mathrm{~m} M$ deoxynucleoside triphosphates, $1 \times$ buffer for $P f u$ DNA polymerase and $2.5 \mathrm{U} P f u$ DNA polymerase. After an initial denaturation step $(2 \mathrm{~min}$ at $368 \mathrm{~K}), 30$ cycles consisting of $30 \mathrm{~s}$ at $368 \mathrm{~K}, 20 \mathrm{~s}$ at $333 \mathrm{~K}$ and $4 \mathrm{~min}$ at $341 \mathrm{~K}$ were carried out, followed by a terminal elongation step (4 min at $341 \mathrm{~K})$. The PCR mix was 
separated on a $1 \%$ agarose gel and the expected $3.15 \mathrm{kbp}$ fragment was isolated with a Qiaquick spin column. After restriction with NdeI and XhoI, the PCR fragment was again purified with a Qiaquick spin column and ligated with an NdeI/XhoIrestricted pET24a (Novagen), resulting in pET24acrB ${ }_{\text {His. }}$.

E. coli C43(DE3) cells (Miroux \& Walker, 1996) were transformed with $\mathrm{pET} 24 \mathrm{acrB}_{\mathrm{His}}$ and a colony on an overnight-incubated LB plate containing $50 \mu \mathrm{g} \mathrm{ml}^{-1}$ kanamycin $\left(\mathrm{Kan}^{50}\right)$ was picked to inoculate $4 \mathrm{ml} \mathrm{LB}$ $\mathrm{Kan}^{50}$. This preculture was grown overnight at $310 \mathrm{~K}$ with shaking at $180 \mathrm{rev} \mathrm{min}^{-1}$ and used to inoculate 11 Terrific Broth (Becton, Dickinson and Co.) $\mathrm{Kan}^{50}$. The culture was grown for about 2-3 $\mathrm{h}$ to an $\mathrm{OD}_{600}$ of 0.6 and the culture was then cooled down on ice for 5-10 min and supplemented with $0.5 \mathrm{mM}$ IPTG (final concentration). Growth was continued for $3.5 \mathrm{~h}$ at $303 \mathrm{~K}$ with shaking at

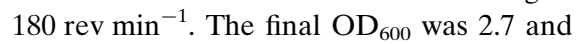
about $7.5 \mathrm{~g}$ of wet packed cells were harvested. Cells were resuspended in $20 \mathrm{ml}$ $20 \mathrm{~m} M$ Tris- $\mathrm{HCl}$ pH 8.0 containing $0.5 \mathrm{M}$ $\mathrm{NaCl}, 2 \mathrm{mM} \mathrm{MgCl}, 0.2 \mathrm{~m} M$ diisopropylfluorophosphate and a trace amount of DNase I. Cells were disrupted by passing the suspension twice through a French pressure chamber at $82.7 \mathrm{MPa}$. The suspension was centrifuged at $277 \mathrm{~K}$ for $10 \mathrm{~min}$ at $10000 \mathrm{~g}$ and the supernatant was centrifuged at $277 \mathrm{~K}$ for $1 \mathrm{~h}$ at $131000 \mathrm{~g}$. The membrane pellet was resuspended in $10 \mathrm{ml} 20 \mathrm{~m} M$ Tris$\mathrm{HCl}$ pH 8.0 containing $0.5 \mathrm{M} \mathrm{NaCl}$ (to approximately $30 \mathrm{mg} \mathrm{ml}^{-1}$ protein) and stored in liquid nitrogen until use.

Membranes (3.6 ml; approximately $110 \mathrm{mg}$ of protein) were solubilized by addition of $4.4 \mathrm{ml}$ buffer $A\left[10 \mathrm{~m} M \mathrm{KP}_{\mathrm{i}} \mathrm{pH}\right.$ 7.8, $100 \mathrm{~m} M \mathrm{NaCl}, 10 \%$ glycerol, $10 \mathrm{~m} M$ imidazole $\mathrm{pH} 8.0$ and $0.05 \%$ cyclohexyl- $n$ hexyl- $\beta$-D-maltoside (CHM; Calbiochem)] and $2 \mathrm{ml} \mathrm{CHM} \mathrm{(10 \%} \mathrm{stock} \mathrm{solution)} \mathrm{and}$ incubated for $1 \mathrm{~h}$ at $277 \mathrm{~K}$ in the cold room while rotating (on a blood-wheel). The mixture was centrifuged for $1 \mathrm{~h}$ at $145000 \mathrm{~g}$ at $277 \mathrm{~K}$ and the supernatant was applied onto an $\mathrm{Ni}^{2+}$-NTA agarose column $(1 \mathrm{ml}$ bed volume) pre-equilibrated in buffer $A$. The column was washed with $35 \mathrm{ml}$ buffer $A$ and subsequently washed with $25 \mathrm{ml}$ buffer $B(50 \mathrm{~m} M$ imidazole $\mathrm{pH} 7.0,100 \mathrm{~m} M \mathrm{NaCl}$, $10 \%$ glycerol and $0.05 \% \mathrm{CHM}) . \mathrm{AcrB}_{\mathrm{His}}$ was eluted in $10 \mathrm{ml}$ buffer $C(200 \mathrm{mM}$ imidazole $\mathrm{pH} 7.0,100 \mathrm{mM} \mathrm{NaCl}, 10 \%$ glycerol and $0.05 \% \mathrm{CHM}$ ) and concentrated to $0.5 \mathrm{ml}$ using a Ultrafree-4 (BioMax-50K, Millipore) spin column in a Hereaus centri-

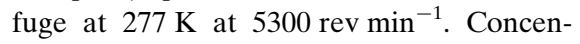
trated protein was washed with $4.5 \mathrm{ml}$
$10 \mathrm{~m} M$ Na HEPES pH 7.0 containing $0.05 \%$ $\mathrm{CHM}$ and again concentrated to a concentration of about $10-20 \mathrm{mg} \mathrm{ml}^{-1}$. Before crystallization setups were carried out, the sample was passed through a $100 \mathrm{~nm}$ filter (Anodisc 13, Whatman).

\subsection{Crystallization}

The hanging-drop vapour-diffusion method was used with Hampton Research screens to identify promising conditions. Grid screens were prepared in order to investigate the effect of different salts $\left(\mathrm{NaCl}, \mathrm{LiCl}, \mathrm{KCl}\right.$ and $\mathrm{Na}_{2} \mathrm{SO}_{4}$ ), $\mathrm{pH}$ (varied over $\mathrm{pH} 6.5-8.5$ in 0.5 steps) and precipitant conditions [PEG 4000 over the range 4-12\% (in 1\% steps) and PEG 400 over the range $6-20 \%$ (in $2 \%$ steps)]. Protein solution (10$20 \mathrm{mg} \mathrm{ml}^{-1}$ ) was mixed in a 1:1 ratio with mother liquor (normally $2.5 \mu \mathrm{l}$ solution plus $2.5 \mu \mathrm{l}$ mother liquor) and suspended over $0.5 \mathrm{ml}$ reservoir solution. Samples were incubated at $289 \mathrm{~K}$.

\subsection{Cryocooling and X-ray diffraction data measurement}

Crystals were subjected to cryoprotection using two different cryoprotectants, glycerol (CryoG1 and CryoG2) and PEG 400 (CryoP1 and CryoP2). A single crystal was transferred to a droplet of solution containing, for case (a), 0.1 $M$ Na HEPES pH 7.5, $0.1 M \mathrm{NaCl}, 5 \%$ PEG 4000, 5\% glycerol and $0.05 \%$ CHM (CryoG1). This droplet was then suspended over $0.5 \mathrm{ml}$ of $0.1 M \mathrm{Na}$ HEPES pH 7.5, $0.1 M \mathrm{NaCl}, 5 \%$ PEG 4000, 30\% glycerol and 0.05\% CHM (CryoG2). In case (b), the crystal was transferred to a droplet of solution containing $0.1 \mathrm{M} \mathrm{Na}$ HEPES pH 7.5, $0.1 M \mathrm{NaCl}$, $10 \%$ PEG 400 and $0.05 \%$ CHM (CryoP1). This droplet was suspended over $0.5 \mathrm{ml}$ $0.05 M$ Na HEPES pH 7.5, $0.05 M \mathrm{NaCl}, 15 \%$ PEG 400 and $0.025 \%$ CHM (CryoP2 1:1 diluted with $\mathrm{H}_{2} \mathrm{O}$ ). After overnight incubation at $289 \mathrm{~K}$, the crystals were collected with a loop and in case $(a)$ directly frozen into liquid nitrogen or in case $(b)$ transferred to a droplet of $0.1 M \mathrm{Na}$ HEPES pH 7.5, $0.1 M \mathrm{NaCl}, 30 \%$ PEG 400 and $0.05 \%$ CHM (CryoP2). After 1 min incubation, the crystal was frozen in liquid nitrogen.

In-house preliminary X-ray diffraction data were measured using a Schneider (Offenburg,

Figure 2
Germany) $\mathrm{Cu} K \alpha$ rotating-anode X-ray generator operating at $40 \mathrm{kV}$ and $100 \mathrm{~mA}$ and equipped with focusing mirror optics and a MAR Research $345 \mathrm{~mm}$ imaging-plate area detector. Data sets from native crystals at $100 \mathrm{~K}$ were collected at the DESY synchrotron, Hamburg, EMBL beamlines BW7A, BW7B and X11 using MAR Research (Hamburg, Germany) CCD and image-plate detectors. Data sets were also collected at beamline X06SA of the Swiss Light Source (Villigen, Switzerland) on a MAR Research CCD detector.

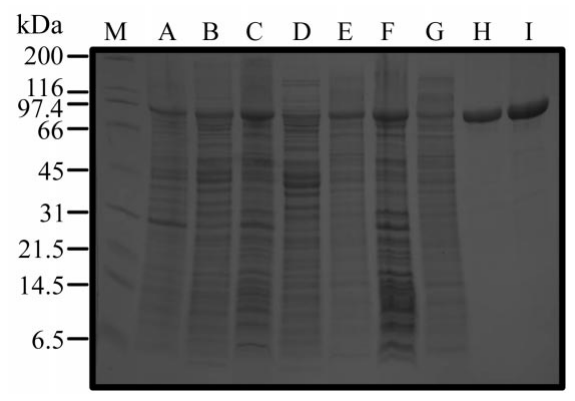

Figure 1

SDS-PAGE analysis of the synthesis and purification of $\mathrm{AcrB}_{\mathrm{His}} \cdot 10 \%$ SDS-PAGE analysis, gel stained with Coomassie. Lane $\mathrm{M}$ : broad-range marker (BioRad, $2 \mu \mathrm{g}$ ); lane A, pellet fraction after French Press and low-spin centrifugation $(25 \mu \mathrm{g})$; lane $\mathrm{B}$, supernatant fraction after French Press and low-spin centrifugation $(25 \mu \mathrm{g})$; lane C, E. coli C43(DE3)/ pET24acrB ${ }_{\text {His }}$ membranes $(25 \mu \mathrm{g})$; lane D, E. coli C43(DE3)/pET24acrB ${ }_{\text {His }}$ cytoplasm $(25 \mu \mathrm{g})$; lane E, detergent extract of E. coli $\mathrm{C} 43(\mathrm{DE} 3) / \mathrm{pET} 24 \mathrm{acrB} \mathrm{His}_{\mathrm{s}}$ membranes $(25 \mu \mathrm{g})$; lane $\mathrm{F}$, extract from $E$. coli C43(DE3)/pET24acrB ${ }_{\text {His }}$ membranes $(25 \mu \mathrm{g})$; lane G, $\mathrm{Ni}^{2+}$-NTA chromatography (10 $\mathrm{m} M$ imidazole) flowthrough fraction $(25 \mu \mathrm{g})$; lane $\mathrm{H}$, purified and concentrated $\mathrm{AcrB}_{\mathrm{His}}(5 \mu \mathrm{g})$; lane I, purified and concentrated $\mathrm{AcrB}_{\mathrm{His}}(10 \mu \mathrm{g})$.

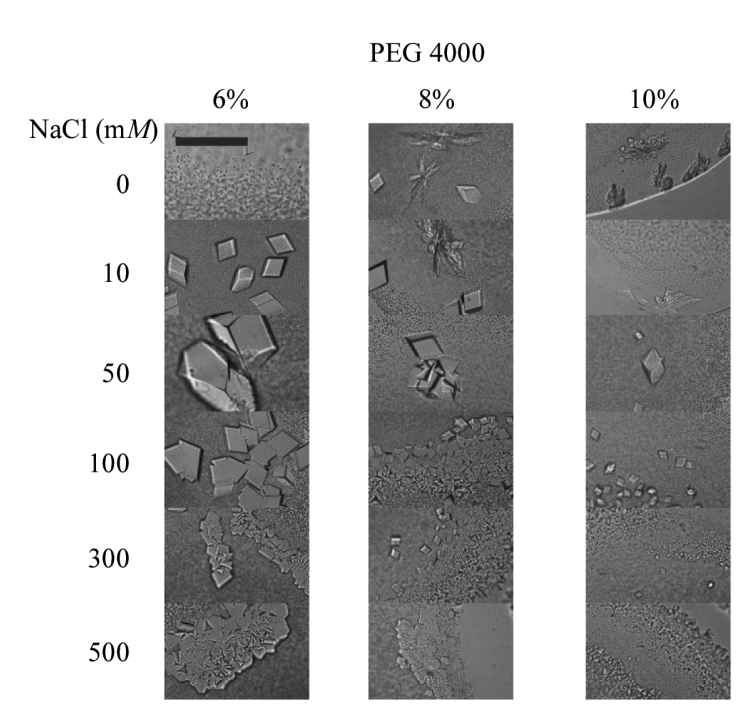

Crystal growth of $\mathrm{Ni}^{2+}-\mathrm{NTA}$-purified $\mathrm{AcrB}_{\mathrm{His}}$. The reservoir solution contained $0.1 M$ Na HEPES $\mathrm{pH} 7.5$, precipitant and salt as indicated. The bar represents about $0.5 \mathrm{~mm}$. 
Table 1

Data quality of a native AcrB crystal ( $a=b=143.1$, $\left.c=513.3 \mathrm{~A}, \alpha=\beta=90, \gamma=120^{\circ}\right)$ collected at beamline BW7A of EMBL/DESY.

\begin{tabular}{llll}
\hline Resolution range $(\AA)$ & $50-3.5$ & $4.0-3.7$ & $3.7-3.5$ \\
\hline Unique reflections & 26016 & 4540 & 3930 \\
Completeness $(\%)$ & 99.7 & 99.9 & 99.9 \\
Multiplicity & 4.6 & 4.6 & 4.6 \\
$I / \sigma(I)$ & 9.9 & 3.7 & 2.9 \\
$R_{\text {meas }} \dagger(\%)$ & 9.9 & 43.7 & 61.5 \\
\hline
\end{tabular}

$\dagger$ Diederichs \& Karplus (1997)

\section{Results and discussion}

$\mathrm{AcrB}_{\text {His }}$ could be purified in a single step using $\mathrm{Ni}^{2+}$-NTA chromatography. SDSPAGE analysis revealed the presence of a single band after staining with Coomassie with an electrophoretic mobility of approximately $100 \mathrm{kDa}$ (Fig. 1).

The theoretical molecular weight of $\mathrm{AcrB}_{\mathrm{His}}$ was calculated to be $114.6 \mathrm{kDa}$; however, aberrant electrophoretic behaviour is common for membrane proteins (Newman et al., 1981; Pos et al., 1994). After the first crystals were obtained by sittingdrop vapour diffusion from Memfac solution 30 (Hampton Research), crystals of native $\mathrm{AcrB}_{\mathrm{His}}$ were grown at $293 \mathrm{~K}$ from hanging drops containing $2.5 \mu \mathrm{l}$ of $17 \mathrm{mg} \mathrm{ml}^{-1}$ $\mathrm{AcrB}_{\mathrm{His}}$ and $2.5 \mu \mathrm{l}$ of reservoir solution containing 0.1 $M$ Na HEPES pH 7.5, 6-10\% PEG 4000 and $0-500 \mathrm{~m} M \mathrm{NaCl}$ (Fig. 2). Crystals grown in this solution could reach dimensions of up to $700 \mu \mathrm{m}$ in $4-5 \mathrm{~d}$. However, these larger crystals were not amenable to cryoprotection by immersion into liquid nitrogen and cooling by evaporating nitrogen during data collection. We found that crystals larger than $400 \times 400 \times$ $400 \mu \mathrm{m}$ could not be used for data set collection owing to high mosaicity after

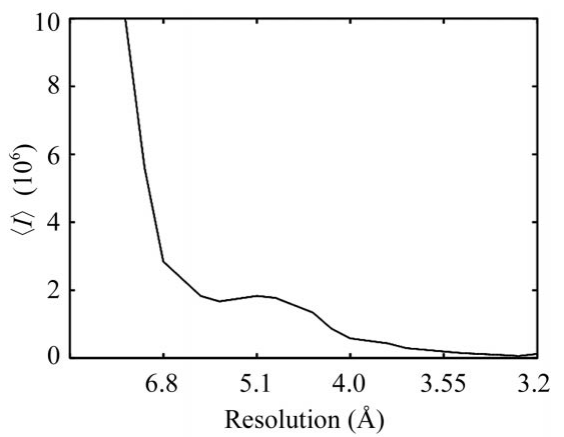

Figure 3

Wilson plot for AcrB.

freezing. However, smaller crystals diffracted to $3.0 \AA$.

$\mathrm{AcrB}_{\mathrm{His}}$ was crystallized in space group $R 32$, with unit-cell parameters $a=b=143$, $c=513 \AA$. The solvent content of the crystals is about $72 \%$ if one assumes one molecule per asymmetric unit. Spots were visible to a resolution of $3.0 \AA$; typical data-collection results are shown in Table 1 . The possible molecular packing in space group $R 32$ together with the fact that AcrA exists as a trimer (Zgurskaya \& Nikaido, 2000b) suggests that AcrB might also form a trimeric entity.

Crystals were sensitive to radiation damage, as is apparent from the comparison of images (not shown) taken at the beginning and end of a data set collection, which took about 1.5 to $8 \mathrm{~h}$ at SLS and DESY beamlines, respectively. Wilson-plot data are shown in Fig. 3. The intensity of diffraction spots is drastically reduced beyond $6 \AA$; the mean temperature factor as calculated from the Wilson plot in the 4.0-3.5 range is about $100 \AA^{2}$.

A search for suitable heavy-atom derivatives of $\mathrm{AcrB}_{\mathrm{His}}$ is under way. Preliminary results indicate that MIR phasing is unlikely to succeed owing to high anisomorphism even between native data sets, whereas structure solution by MAD should be possible.

We thank the staff at EMBL/DESY and SLS synchrotron beamlines for support. KMP would like to thank P. Dimroth for his continuous help and support with this work.

\section{References}

Avila-Sakar, A. J., Misaghi, S., Wilson-Kubalek, E. M., Downing, K. H., Zgurskaya, H., Nikaido, H. \& Nogales, E. (2001). J. Struct. Biol. 136, 8188.

Diederichs, K. \& Karplus, P. A. (1997). Nature Struct. Biol. 4, 269-275.

Felmingham, D. \& Washington, J. (1999). J. Chemother. 11, 5-21.

Fralick, J. A. (1996). J. Bacteriol. 178, 5803-5805.

Koronakis, V., Sharff, A., Koronakis, E., Luisi, B. \& Hughes, C. (2000). Nature (London), 405, 914-919.

Miroux, B. \& Walker, J. E. (1996). J. Mol. Biol. 260, 289-298.

Newman, N. J., Foster, D. L., Wilson, T. H. \& Kaback, H. R. (1981). J. Biol. Chem. 256, 11804-11808.

Nikaido, H. \& Zgurskaya, H. I. (2001). J. Mol. Microbiol. Biotechnol. 3, 215-218.

Okusu, H., Ma, D. \& Nikaido, H. (1996). J. Bacteriol. 178, 306-308.

Pos, K. M., Bott, M. \& Dimroth, P. (1994). FEBS Lett. 347, 37-41.

Sambrook, J., Fritsch, E. F. \& Maniatis, T. (1989). Molecular Cloning: A Laboratory Manual, 2nd ed., Cold Spring Harbor: Cold Spring Harbor Laboratory Press.

Tseng, T. T., Gratwick, K. S., Kollman, J., Park, D., Nies, D. H., Goffeau, A. \& Saier, M. H. Jr (1999). J. Mol. Microbiol. Biotechnol. 1, 107125.

Zgurskaya, H. I. \& Nikaido, H. (1999). Proc. Natl Acad. Sci. USA, 96, 7190-7195.

Zgurskaya, H. I. \& Nikaido, H. (2000a). Mol. Microbiol. 37, 219-225.

Zgurskaya, H. I. \& Nikaido, H. (2000b). J. Bacteriol. 182, 4264-4267. 